\title{
IDENTIFICAÇÃO DE ÁRVORES MATRIZES DE SEIS ESPÉCIES ALÓGAMAS EM UM FRAGMENTO FLORESTAL VISANDO A PRODUÇÃO DE MUDAS COM VARIABILIDADE GENÉTICA
}

\begin{abstract}
Thiago Augusto da Silva - Tecnólogo em Gestão Ambiental, bacharelando em Engenharia Ambiental pela
Universidade Federal de Alfenas - Campus Poços de Caldas, MG, thiagobminas@hotmail.com. Lilian Vilela Andrade Pinto - Engenheira Florestal, D.Sc., Professora do Instituto Federal de Educação, Ciência e Tecnologia do Sul de Minas Gerais - Campus Inconfidentes, lilianvap@gmail.com.
\end{abstract}

\section{RESUMO}

O presente estudo teve como objetivo estudar a população de seis espécies arbóreas nativas de interesse para a recuperação de áreas degradadas em um fragmento de floresta estacional semidecidual localizado no Instituto Federal de Educação, Ciência e Tecnologia do Sul de Minas Gerais, Campus Inconfidentes. Os indivíduos das seis espécies (três pioneiras e três climáxicas) tiveram suas características morfológicas (circunferência à altura do peito - CAP, altura e tortuosidade) avaliadas, foram demarcados com plaquetas de metal e georreferenciados para posterior identificação dos indivíduos ideais a se fazer a coleta de sementes com vistas à produção de mudas com variabilidade genética. Esta identificação foi feita através do tamanho efetivo $(\mathrm{Ne})$ e da distância mínima de $100 \mathrm{~m}$ recomendada pela literatura entre árvores porta-sementes. Avaliou-se também, o efeito de borda no fragmento e a população mínima viável recomendada para cada espécie, de modo que tenham uma variabilidade genética que não traga riscos de extinção da espécie no local. Os indivíduos amostrados dentro do fragmento de 3,38 hectares tiveram pequenas distâncias entre si, resultando em poucas árvores capazes de serem provedoras de sementes, assim como a população mínima viável das espécies ficaram muito abaixo do recomendado. Os resultados sugerem que tende a ocorrer declínio nas populações em curto prazo.

Palavras-chave: tamanho efetivo, distribuição espacial, população mínima viável, efeito de borda.

\section{ABSTRACT}

In this work were studied six native arboreal species of interest to the recovery of degraded areas, located in a forest fragment on the Federal Institute for Education, Science and Technology, campus of the Inconfidentes, Minas Gerais. All individuals of six species (three pioneer and three climax) had their morphological characteristics (circumference to the height of the chest, height and tortuosity) evalueted and were demarcated with platelets of metal and georeferenced for later identification of individuals ideals for making the collection of seeds to produce seedlings with genetic diversity. This identification was made through the effective size (Ne) and of the distance recommended by the literature among port-seed trees. It was also evaluated, the edge effect in the fragment and the minimum viable population recommended of each species so that they have a genetic variability that does not brings risks of extinction of the species on site. The individuals sampled inside of the fragment of 3,38 hectares had small distances between them, resulting in few trees capable of being suppliers of seeds, as well as the minimum viable population that were a lot below recommended. The results suggest that it tends to occur decline in the populations in a short-term.

Key-words: effective size, spatial distribution, minimum viable population, edge effect. 


\section{INTRODUÇÃO}

Nas últimas décadas vem-se reconhecendo que a perda de áreas florestadas na Terra tem significativa parcela de culpa nas mudanças climáticas globais e que a extinção de espécies vegetais e animais é um perigo para a sustentabilidade da vida. As comunidades, principalmente as de maior diversidade, representam um patrimônio nacional de grande valor científico e econômico.

A diversidade representa um patrimônio, também, sob ponto de vista genético, pois cada ser vivo tem um material genético diferenciado, formando um "banco de dados" de valor inestimável a ser empregado pela Engenharia Genética e pela Biotecnologia (Sariego, 2002).

A fragmentação de grandes biomas ou "hot spots" como a Mata Atlântica, resultado da transformação da paisagem, torna cada vez mais difícil a conservação da sua rica biodiversidade. Porém novos conceitos teóricos, se consistentemente embasados através de experimentação de campo, podem minimizar os problemas decorrentes do isolamento (Zaú, 1998).

Geralmente, após as atividades de desflorestamento, sobram fragmentos espalhados distantemente uns dos outros, gravemente perturbados e localizados em áreas não interessantes a atividades agropecuárias, o que dificulta a circulação de genes entre plantas não aparentadas, causando depressão por endogamia.

Os efeitos negativos que o ambiente vem sofrendo por ações antrópicas de desenvolvimento econômico e social podem ser atenuados em grande parte, buscando um futuro mais sustentável, se as instituições públicas e privadas tornarem-se eficazes quanto a destinação de recursos para a implantação de medidas de recomposição e compensação ambiental, previstas nos respectivos EIAS/ RIMAS, PRADS etc.

Sendo o reflorestamento uma das ações de compensação ambiental mais indicada, deve atentar-se na importância da produção de mudas de boa qualidade. Entende-se por isso, plantas resultantes de sementes com a maior diversidade genética possível entre si. É muito comum o uso de poucas árvores matrizes para a coleta de sementes, às vezes uma só, sendo escolhidas as de acesso mais fácil, como de arborização urbana (Rogalski et al., 2005).

Isto acarreta perda da variabilidade genética, que pode vir a afetar a sustentabilidade da futura vegetação, reduzindo o potencial que as populações naturais têm de se adaptarem às mudanças ambientais e problemas como baixa porcentagem de germinação e baixa resistência (Melo Júnior et al., 2004; Yamamoto \& Silva Filho, 2004).

Dentre os vários aspectos que devem ser considerados nos programas de produção de sementes florestais citados por Davide et al. (2000) estão o número de matrizes coletadas e a distância entre matrizes, foco deste estudo.

Assim, o presente estudo teve como objetivo geral dar suporte na coleta de sementes visando a produção de mudas arbóreas com diversidade genética em ajuste com a literatura, e como objetivos específicos conhecer o tamanho efetivo populacional das espécies, a população mínima viável (PMV), indicar os indivíduos ideais (árvores matrizes) a se fazer a coleta de sementes e saber se há efeito de borda no fragmento.

\section{MATERIAIS E MÉTODOS}

A área do estudo situa-se na Fazenda Experimental do Instituto Federal de Educação, Ciência e Tecnologia do Sul de Minas Gerais, Campus Inconfidentes, tendo as coordenadas geográficas: $22^{\circ} 19^{\prime} 1,2^{\prime \prime}$ de latitude S e $46^{\circ} 19^{\prime} 40,8^{\prime \prime}$ de longitude W, altitude média de 855 metros. O clima é o Tropical de Altitude Cwa (Köppen, 1931) com precipitação média de $1744 \mathrm{~mm}$ e temperatura média anual de $20^{\circ} \mathrm{C}$ (Antunes, 


\section{6).}

O fragmento florestal em estudo apresenta uma área de 3,38ha, faz parte da reserva legal do Campus Inconfidentes, foi, há anos atrás, utilizado como pastagem e há cerca de 30 anos, deixado em pousio. Ao norte e ao sul do fragmento em estudo encontram-se mais dois fragmentos, a oeste há um lago artificial destinado à criação de peixes e a leste uma pastagem.

As espécies arbóreas foram selecionadas segundo seu Grupo Ecológico (GE), totalizando seis espécies, três espécies pioneiras (Croton floribundus, Casearia sylvestris e Croton urucurana) e três espécies clímax (Machaerium villosum, Zanthoxyllum rhoifolium e Platycyamus regnellii). Estas foram selecionadas em razão de sua ocorrência em um fragmento de floresta estacional semidecidual em estágio secundário inicial de regeneração, como é o caso do fragmento em estudo, e por ser de grande importância na recuperação de áreas perturbadas e degradas da região. Todos os indivíduos destas espécies, presentes no fragmento, com DAP superior a $5 \mathrm{~cm}$ foram demarcados com GPS e com plaquetas de metal presas por pregos, indicando o respectivo número da espécie e o número do indivíduo. Os indivíduos demarcados foram dispostos em mapas e as distâncias entre os de mesma espécie foram obtidas utilizando o software AutoCad ${ }^{\circledR}$ 2004. As características morfológicas avaliadas em cada indivíduo demarcado foram altura, grau de tortuosidade e CAP. A densidade de indivíduos de cada espécie presente no fragmento foi calculada por hectare.

O tamanho efetivo $(\mathrm{Ne})$ populacional foi calculado seguindo as equações de Vencovsky (1987) sem controle gamético (equação 1) e com controle gamético (equação 2).

Equação $1 \quad\left(N e=n / \frac{n-1}{4 F}+1\right)$
Equação $2 \quad\left(N e=n / \frac{n}{4 F}+\frac{3}{4}\right)$

Em que n é igual ao número de sementes e F é igual ao número de plantas mãe das quais as sementes serão colhidas.

Para se chegar aos valores da população mínima viável (PMV) de 150 e 1500 para conservação da população a curto e longo prazo, respectivamente, proposta por Nunney e Campbell (1993) citado por Silva (2006), foi utilizada a equação 3 .

Equação $3\left(P M V=N e_{\text {referéncia }} / \frac{N e}{n}\right)$

Onde Nereferência é o tamanho efetivo populacional de referência, $\mathrm{Ne}$ é o tamanho efetivo populacional com controle gamético e $n$ é o número de indivíduos amostrados.

O número de indivíduos amostrados (20) seguiu a proposta de Kageyama \& Gandara (2001), sugestão fundamentada em Vencovsky (1987) e Frankel \& Soulé (1981) citado por Gusson et al. (2006), para a obtenção de um tamanho efetivo de 50, tamanho este que visa a garantia da representatividade da integridade genética da população durante a coleta.

Foram consideradas árvores matrizes para a coleta de sementes, os indivíduos distanciados de 100 metros ou mais entre si, seguindo a recomendação de César et al. (1988), Gray (1990), Rosado \& Carvalho (2001), Duque Silva et al. (2006) e Silva et al. (2007).

O índice de circularidade é definido como a raiz quadrada da área do fragmento $(A f)$, dividido pela área $(A c)$ de um círculo de mesmo perímetro $(P)$ do fragmento. Assim, com o perímetro do fragmento, calcula-se o raio $(R) \operatorname{com} R=P / 2 \pi$. Com base em $\mathrm{R}$, determina-se a área $(A c=\pi R 2)$ de um círculo de mesmo perímetro (Borges et al., 2004). 
Segundo Viana \& Pinheiro (1998) os fragmentos florestais são classificados da seguinte forma: fragmentos com fator de forma superior a 0,8 são considerados arredondados; entre 0,6 e 0,8 são alongados e inferior a 0,6 , muito alongados.

O perímetro e a área do fragmento em estudo foram obtidos com auxílio do GPS e software AutoCad ${ }^{\circledR}$, sendo que o fragmento possui área de 3,38 ha e perímetro de 757 metros.

\section{RESULTADOS E DISCUSSÕES}

Das espécies estudadas, as espécies Casearia sylvestris e Croton floribundus, pertencentes ao grupo ecológico das pioneiras, são as de maior ocorrência no fragmento, visto que este se compõe por floresta secundária em estágio intermediário de regeneração e sendo, portanto, esperado maior densidade para as espécies de grupos ecológicos iniciais.

A espécie Croton urucurana mesmo pertencendo ao grupo ecológico das pioneiras, apresentou baixa densidade em relação às outras duas do mesmo grupo ecológico. Isto se explica pelo fato de ser uma espécie seletiva higrófita, tendo sua ocorrência em lugares úmidos (Lorenzi, 2002). Observa-se que sua distribuição foi bastante agrupada e deu-se em locais mais baixos, onde há maior influência do lençol freático.

Platycyamus regnellii e Zanthoxyllum rhoifolium, espécies climáxicas, foram as espécies de menor densidade, já que são mais ocorrentes em florestas primárias, onde já se passaram todos os estágios sucessionais. Os indivíduos da espécie Machaerium villosum, espécie climáxica, apresentou um número um pouco maior que Croton urucurana, espécie pioneira, pois segundo Lorenzi (2002) tem característica de se adaptar tanto no interior de matas primárias densas como em formações secundárias.

Os tamanhos efetivos $(\mathrm{Ne})$ das seis espécies em estudo encontram-se na Tabela 1. Nota-se, portanto, que o controle gamético (C) tem grande importância na coleta de germoplasma, devendo-se coletar sementes do maior número de plantas (F), e de preferência, quantidades iguais de cada uma.

As espécies Zanthoxylum rhoifolium (mamica-de-porca) e Platycyamus regnellii (pau-pereira) apresentam tamanhos efetivos abaixo do recomendado que é Ne igual a 50 para preservação de suas populações segundo Kageyama \& Gandara (2001), tamanho este que garantiria a integridade genética da população. Este Ne é alcançado segundo os autores com a amostragem de, no mínimo, 20 plantas. Assim, coletando as sementes de 20 plantas significa que elas estariam representando geneticamente 50 plantas da população original.

TABELA 1. Tamanhos efetivos (Ne) inerentes a amostras de $\mathrm{n}=100$ sementes colhidas de $\mathrm{F}$ plantas, em espécie alógama, sem (S) ou com (C) controle gamético feminino, com destaque para o número de indivíduos encontrados das espécies em estudo.

\begin{tabular}{|c|c|c|c|c|c|c|c|c|c|c|c|c|}
\hline \multicolumn{2}{|l|}{$\mathbf{F}$} & & 5 & 10 & 13 & 18 & 20 & 25 & 50 & 72 & 100 & 182 \\
\hline \multirow[t]{2}{*}{ Casearia sylvestris } & \multirow{12}{*}{$\mathrm{Ne}$} & $S$ & 17 & 29 & $\ldots$ & $\ldots$ & $\ldots$ & $\ldots$ & 67 & $\ldots$ & 80 & 88 \\
\hline & & $\mathrm{C}$ & 17 & 31 & $\ldots$ & $\ldots$ & $\ldots$ & $\ldots$ & 80 & $\ldots$ & 100 & 113 \\
\hline \multirow[t]{2}{*}{ Croton floribundus } & & S & 17 & 29 & $\ldots$ & $\ldots$ & $\ldots$ & $\ldots$ & 67 & 74 & 80 & $\cdots$ \\
\hline & & $\mathrm{C}$ & 17 & 31 & $\ldots$ & $\ldots$ & $\ldots$ & $\ldots$ & 80 & 91 & 100 & •• \\
\hline \multirow[t]{2}{*}{ Croton urucurana } & & $\mathrm{S}$ & 17 & 29 & $\ldots$ & $\ldots$ & 45 & & 67 & $\ldots$ & 80 & $\ldots$ \\
\hline & & $\mathrm{C}$ & 17 & 31 & ... & 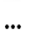 & 50 & & 80 & $\ldots$ & 100 & \\
\hline \multirow[t]{2}{*}{ Macchaerium villosum } & & S & 17 & 29 & ... & $\ldots$ & $\ldots$ & 50 & 67 & $\ldots$ & 80 & $\cdots$ \\
\hline & & $\mathrm{C}$ & 17 & 31 & $\ldots$ & $\ldots$ & $\ldots$ & 57 & 80 & $\ldots$ & 100 & \\
\hline \multirow[t]{2}{*}{ Zanthoxyllum rhoifolium } & & $\mathrm{S}$ & 17 & 29 & 34 & $\ldots$ & $\ldots$ & $\ldots$ & 67 & $\ldots$ & 80 & $\ldots$ \\
\hline & & $\mathrm{C}$ & 17 & 31 & 37 & $\ldots$ & $\ldots$ & $\ldots$ & 80 & $\ldots$ & 100 & \\
\hline \multirow[t]{2}{*}{ Platycyamus regnellii } & & $S$ & 17 & 29 & $\cdots$ & 42 & $\ldots$ & $\ldots$ & 67 & $\ldots$ & 80 & $\cdots$ \\
\hline & & C & 17 & 31 & $\ldots$ & 47 & $\ldots$ & $\ldots$ & 80 & $\ldots$ & 100 & \\
\hline
\end{tabular}

As demais espécies em estudo alcançaram o valor de $\mathrm{Ne}$ igual a 50. Entretanto, quanto maior o número de plantas amostradas melhor, pois aumentam-se as chances de se amostrar alelos raros, como citado por Vencovsky (1987).

A população mínima viável de todas as espécies em estudo não foi alcançada, nem 
mesmo a curto prazo (Tabela 2). Isso indica a fragilidade do fragmento em estudo no que tange a densidade de suas populações, uma vez que segundo Scariot (1998) se a área de uma reserva natural está abaixo do tamanho mínimo necessário para que seja mantida a população de uma espécie, significa então que a espécie estará em risco de extinção nessa reserva, pois cada espécie tem um tamanho mínimo viável de população abaixo do qual, torna-se difícil encontrar parceiros para o acasalamento, produzir prole geneticamente viável (em espécies de reprodução cruzada), sobreviver a flutuações aleatórias no tamanho, e produzir novas populações colonizadoras a longo prazo.

Avaliando as distâncias entre os indiví- duos, verificou-se que em nenhuma espécie foi possível chegar ao objetivo de 20 árvores matrizes distanciadas em 100 metros (Tabela 3), que é recomendado por César et al. (1988), Gray (1990), Rosado \& Carvalho (2001), Duque Silva et al. (2006) e Silva et al. (2007).

$\mathrm{O}$ pequeno número de árvores matrizes selecionadas explica-se, em grande parte, pelo fato de o fragmento ser de tamanho pequeno (3,38ha). Assim, recomenda-se que mais trabalhos da mesma natureza sejam feitos no restante da Fazenda Experimental que se localiza o fragmento, de forma que sejam conhecidas as matrizes de outros fragmentos e conheça-se, inclusive, a diversidade dos fragmentos que circundam o fragmento estudado neste trabalho.

TABELA 2. Populações mínimas viáveis das seis espécies estudadas. Onde $n$ é o número de indivíduos amostrados.

\begin{tabular}{|l|c|c|c|c|c|}
\hline Espécie & Tamanho efetivo populacional & $\mathbf{n}$ & $\mathbf{N e} / \mathbf{n}$ & \multicolumn{2}{|c|}{ PMV } \\
\cline { 4 - 6 } & com controle gamético (Ne) & & & $150^{*}$ & $1500^{* *}$ \\
\hline Casearia sylvestris & 113 & 182 & 0,62 & 242 & 2419 \\
\hline Croton floribundus & 91 & 72 & 1,26 & 119 & 1190 \\
\hline Croton urucurana & 50 & 20 & 2,5 & 60 & 600 \\
\hline $\begin{array}{l}\text { Macchaerium } \\
\text { villosum }\end{array}$ & 57 & 25 & 2,28 & 66 & 658 \\
\hline $\begin{array}{l}\text { Zanthoxyllum } \\
\text { rhoifolium }\end{array}$ & 37 & 13 & 2,85 & 53 & 526 \\
\hline Platycyamus regnellii & 47 & 18 & 2,61 & 57 & 575 \\
\hline
\end{tabular}

* Tamanho efetivo de referência para conservação da espécie a curto prazo (algumas gerações).

** Tamanho efetivo de referência para conservação da espécie a longo prazo (muitas gerações).

TABELA 3. Tamanhos efetivos $(\mathrm{Ne})$ de acordo com o número de matrizes do fragmento, sendo colhidas 50 sementes de cada matriz. $\mathrm{N}=$ sementes, $\mathrm{F}=\mathrm{n}^{\mathrm{o}}$ de matrizes.

\begin{tabular}{|l|c|c|c|}
\hline \multicolumn{1}{|c|}{ Espécie } & N & F & Ne \\
\hline Casearia sylvestris & 350 & 7 & 26 \\
\hline Croton floribundus & 150 & 3 & 11 \\
\hline Cróton urucurana & 150 & 3 & 11 \\
\hline Macchaerium villosum & 200 & 4 & 15 \\
\hline Platycyamus regnellii & 150 & 3 & 11 \\
\hline Zanthoxyllum rhoifolium & 200 & 4 & 15 \\
\hline
\end{tabular}

Os indivíduos selecionados podem ser alterados, mas sempre se atentando para ser mantido os 100 metros entre eles. Nas plantas selecionadas, foram consideradas as de melhor porte (maior altura, maior CAP e menor tortuosidade), quando as distâncias permitiram tal escolha.

Os indivíduos sugeridos como árvores porta-sementes, ainda podem ser aparentados, mesmo com menores chances, mas para esta afirmação sugere-se que sejam feitos estudos com isoenzimas para conhecer realmente $\mathrm{o}$ índice de endogamia das espécies, visto que este trabalho foi realizado com base em dados literários.

O tamanho efetivo das árvores matrizes seguindo a recomendação de Hawkes (1981) 
citado por Vencovsky (1987) de se coletar 50 sementes de cada matriz encontra-se na Tabela 3.Os números alcançados tanto para o tamanho efetivo como para o número de sementes são ínfimos, mostrando que a colheita das sementes deve ser feita de um número bem maior de matrizes e indicando a não sustentabilidade do fragmento para a conservação das espécies e para a coleta das sementes para a produção de mudas em viveiro.

Ovalordoíndicedecircularidadeencontrado para o fragmento em estudo foi de 0,86 . Assim, o fragmento enquadra-se na classificação de Viana \& Pinheiro (1998) como sendo "arredondado", sendo menos sujeito ao efeito de borda. Porém, este resultado é descreditado segundo Saunders et al. (1991) citado por Oliveira et al. (2005) em que diz que fragmentos com até 30 ha são considerados pequenos, podendo apresentar baixa sustentabilidade.

Viana et al. (1992) destacaram que pequenos fragmentos florestais apresentam problemas quanto ao tamanho das populações, por conterem poucos indivíduos, podendo ocorrer o declínio das populações. Mais precisamente, Pereira (1999) citado por Oliveira et al. (2005), diz que fragmentos com área de até 10 ha têm $90 \%$ de sua área afetada pelo efeito de borda. Sendo assim, as espécies florestais do fragmento em estudo correm sérios riscos de sofrerem gargalos genéticos, mesmo apresentando um bom índice de circularidade de acordo com a equação proposta.

$\mathrm{Na}$ área do fragmento, observa-se que os outros dois fragmentos existentes ao seu redor tendem, há certo tempo, unirem-se ao de estudo (situado no meio deles), circunstância que diminuirá os efeitos negativos nas áreas de borda, unindo, inclusive, as populações arbóreas que hoje encontram-se distantes, proporcionando um encontro entre seus bancos de genes.

\section{CONCLUSÕES}

O valor da população mínima viável encontrada para as espécies em estudo é aquém ao recomendado para a conservação das espécies podendo ocorrer declínio nas populações em curto prazo.

As árvores matrizes das espécies Casearia sylvestris (7), Machaerium villosum (4), Zanthoxyllum rhoifolium (4), Croton urucurana (3), Croton floribundus (3) e Platycyamus regnelli (3) não atendem o mínimo para a sustentabilidade de coleta de sementes para a produção de mudas com variabilidade genética.

O efeito borda do fragmento é significativo.

\section{REFERÊNCIAS BIBLIOGRÁFICAS}

ANTUNES, F.Z. Caracterização climática do estado de Minas Gerais. Informe Agropecuário, Belo Horizonte, v.12, n. 138, p. 9-14, Jun.1986.

BORGES, L.F.R.; SCOLFORO, J.R.S.; OLIVEIRA, A.D.; MELLO, J.M.; ACERBI JÚNIOR, F.W.; FREITAS, G.D. Inventário de fragmentos florestais nativos e propostas para seu manejo e o da paisagem. Cerne, Lavras, v. 10, p. 22-38, 2004.

CÉSAR, E. R. G.; SHIMIZU, J. Y.; ROMANELLI, R. Variação entre procedências e progênies de Pinus oocarpa em Angatuba, SP. Boletim de Pesquisa Florestal, Colombo, n. 17, p. 13-24, 1988.

DAVIDE, A C.; FERREIRA, R. A.; FARIA, J. M. R.; BOTELHO, S. A. Restauração de matas ciliares. Informe Agropecuário, , v. 21, n. 207, p. $65-74,2000$.

DUQUE SILVA, L.; HIGA, A. R.; DA SILVA, I. C. Produção de Sementes de Espécies Florestais Nativas em Sistemas Agroflorestais aplicados na Restauração de Reserva Legal e Zonas de Amortecimento de Unidades de Conservação. In: Congresso Brasileiro de Sistemas Agroflorestais, 4., 2006, Anais... Campus dos Goytacazes.

GRAY, R. Professional Seed Collection. In: 
Sowing the Seeds: Direct Seeding and Natural Regeneration Conference, 22-25. 1990. Adelaide Convention Centre. Greening Australia, ACT.

GUSSON, E.; SEBBENN, A. M.; KAGEYAMA, P. Y. Sistema de Reprodução em populações Eschweilera ovata (Cambess.) Miers. Revista Árvore, v. 30, p. 491-502, 2006.

KAGEYAMA, P. Y; GANDARA, F. B. Recuperação de áreas ciliares. In: RODRIGUES, R. R.; LEITÃO FILHO, H. Matas ciliares: conservação e recuperação. 2. ed. São Paulo: Editora da Universidade de São Paulo/Fapesp. p. 249-269. 2001.

KOEPPEN, W. Grundriss der Klimakunde. Zweite verbesserte auflage der "Klimate der Erde”. Berlin: Walter De Gruite Co, 1931.

LORENZI, H. Árvores brasileiras - manual de identificação e cultivo de plantas arbóreas nativas do Brasil, Instituto Plantarum, 2002. v. 2.

MELOJÚNIOR,A.F.; CARVALHO,D.; POVOA, J. R. S.; BEARZOTI, E. Estrutura Genética em populações Naturais de Pequizeiro (Caryocar brasiliense Camb.). Scientia Florestalis, Ribeirão Preto, n. 66, p. 56-65, 2004.

OLIVEIRA, M.L. R.; SOARES, C.P. B.; SOUZA, A. L.; LEITE, H. G. Equações de volume de povoamento para fragmentos florestais naturais do município de Viçosa, Minas Gerais. Revista Árvore, Viçosa, v. 29, n. 2, p. 213-225, 2005.

ROGALSKI, J.M.; BERKENBROCK, I.S.; REIS, A.; REIS, M.S. Sucessão e diversidade como fundamentos básicos na restauração ambiental. In: Simpósio Nacional e Congresso Latino-americano de Recuperação de Áreas Degradadas - SOBRADE, 4., Anais... 2005, Curitiba. p. 433-439, 2005.

ROSADO, S. C. S.; CARVALHO, D. Biodiversidade e conservação de espécies ar- bóreas. Lavras-MG: Editora UFLA, 2001.

SARIEGO, J. C. L. Cientistas alertam para o perigo da "erosão genética". Espaço Sariego. 2002. Acesso em 11 out. 2008. Online. Disponível em <http://paginas.terra.com.br/educacao/ sariego/erosao_genetica.htm>

SILVA, A. C.; ROSADO, S. C. S.; VIEIRA, C. T.; CARVALHO, D. Variação genética entre e dentro de populações de candeia (Eremanthus erythropappus (DC.) MacLeish). Ciência Florestal, v. 17, p. 271-277, 2007.

SILVA, M. S. Diversidade e estrutura genética em populações naturais de Geonoma schottiana Mart. no Parque Forestal Quedas do Rio Bonito. 2006. Trabalho de Conclusão de Curso. (Graduação em Engenharia Florestal) Universidade Federal de Lavras.

VENCOVSKY, R. Tamanho efetivo populacional na coleta e preservação de germoplasma de espécies alógamas. Instituto de Pesquisa e Estudos Florestais - IPEF, Piracicaba, v. 35, p. 79-84, 1987.

VIANA, V.M.;PINHEIRO, L.A.F. V. Conservação da biodiversidade em fragmentos florestais. Série Técnica IPEF, v.12, n.32, p.25-42, 1998.

VIANA, V.M.; TABANEZ,A. J.A. e MARTINEZ, J. L. A. Restauração e manejo de fragmentos florestais. $2^{\circ}$ Congresso Nacional Sobre Essências Nativas - Anais..., vol. 2, p. 400 -406, 1992.

YAMAMOTO, M. A.; SILVA FILHO, D. F. Determinação de árvores matrizes na floresta urbana por um banco de dados relacional. In: VIII Congresso Brasileiro de Arborização Urbana, 8., Anais... 2004, São Paulo. 2004.

ZAÚ, A. S. Fragmentação da Mata Atlântica. Floresta e Ambiente, Rio de Janeiro, v.6, n.1, p.160-170, 1998. 